Artículo científico

(Original paper)

\title{
SEGREGACIÓN ESTACIONAL POR SEXO Y EDAD DE VENADO COLA BLANCA EN POBLACIONES DE VIDA LIBRE Y ENCIERRO EN DURANGO, MÉXICO
}

\author{
WHITE-TAILED DEER SEASONAL SEGREGATION BY SEX AND AGE IN FREE-LIVING \\ AND FENCED POPULATIONS IN DURANGO, MEXICO
}

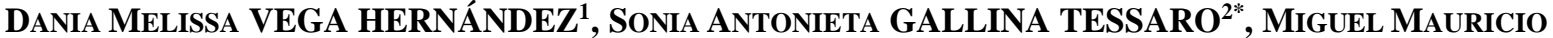 CORREA RAMÍREZ ${ }^{3}$, ISAIAS CHAIREZ HERNÁNDEZ ${ }^{3}$, MIGUEL ANGEL SOTO CÁRDENAS ${ }^{1}$}

\begin{abstract}
${ }^{1}$ Doctorado del Centro Interdisciplinario de Investigación para el Desarrollo Integral Regional, Durango-Instituto Politécnico Nacional. Calle Sigma 119, Fraccionamiento 20 de Noviembre, Durango, Durango, México 34220. <daniavega12@gmail.com>; <miguelsoto06@hotmail.com>

${ }^{2}$ Instituto de Ecología, A.C., Antigua Carretera a Coatepec, 351, El Haya, Veracruz, México 91073. <sonia.gallina@inecol.mx> ${ }^{3}$ Centro Interdisciplinario de Investigación para el Desarrollo Integral Regional, Durango-Instituto Politécnico Nacional. Calle Sigma 119, Fraccionamiento 20 de Noviembre, Durango, Durango, México 34220. <miguel.m.correa.ramirez@ gmail.com>; <ichairez@hotmail.com>

*Autor de correspondencia: <sonia.gallina@inecol.mx>
\end{abstract}

Recibido: 24/09/2018; aceptado: 12/09/2019; publicado en línea: 20/09/2019

Editor responsable: Vinicio Sosa

Vega-Hernández, D. M., Gallina-Tessaro, S. A., Correa-Ramírez M. M., Chairez-Hernández, I., SotoCárdenas, M. A. (2019) Segregación estacional por sexo y edad de venado cola blanca en poblaciones de vida libre y encierro en Durango, México. Acta Zoológica Mexicana (nueva serie), 35, 1-13. https://doi.org/10.21829/azm.2019.3502077

RESUMEN. El venado cola blanca (Odocoileus virginianus) es una especie con valor económico, dado que es la especie cinegética más importante del país, por lo que es indispensable contar con datos confiables sobre su demografía para su mejor manejo. El objetivo de este trabajo fue analizar la segregación estacional por sexo y edad, a partir de grupos fecales, en dos grupos de venado cola blanca, uno en vida libre (UMA Salvador Allende, $3200 \mathrm{ha}$ ) y el otro en un encierro (UMA Molinillos, $300 \mathrm{ha}$ ) ubicados en el estado de Durango. Se colectaron grupos fecales para cada UMA cada dos semanas por 13 meses (del $1^{\circ}$ de marzo 2015 al 31 de marzo 2016 en Salvador Allende y del $1^{\circ}$ de octubre 2015 al 31 de octubre 2016 en Molinillos). Se midió el largo y ancho de 10 pellets fecales por grupo fecal y se calculó el volumen medio, para asignar los grupos fecales a una categoría de edad y sexo mediante la técnica de agrupamiento de conjuntos difusos (fuzzy sets). Se aisló ADN de los pellets fecales y se amplificó un fragmento del gen SRY para determinar el sexo de los animales que depositaron los grupos fecales y comparar con los resultados obtenidos de las medidas morfométricas de los pellets. Los datos espaciotemporales tomados de los grupos fecales, así como su identificación de edad y sexo, se utilizaron para calcular el grado de segregación sexual espacial (CSSE) en cada UMA. Se colectaron 351 grupos fecales frescos para ambas UMA durante todas las épocas del año, encontrando más grupos pertenecientes a hembras. En la población de vida libre se colectó un menor número de grupos fecales (112) que en la población en encierro (273). El grado de segregación espacial fue estadísticamente diferente entre épocas del año siendo mayores en verano en ambas UMA (0.910 para Salvador Allende y 0.943 en Molinillos) cuando ocurren los nacimientos. Los valores más bajos se presentaron en invierno (0.339) en Salvador Allende y en otoño (0.130) en Molinillos, cuando ocurre el celo, lo que indica que el CSSE estuvo regido por el comportamiento reproductivo. No se observó 
correlación entre el índice de segregación espacial y las variables ambientales. Hay que considerar las variaciones debidas a la segregación sexual y edad en cada época del año, ya que pueden afectar los resultados de estimaciones de población mediante la técnica de conteo de grupos fecales, dependiendo de la época en que se realicen, por lo que se recomienda llevar a cabo las estimaciones de población tanto en la época donde se presente el valor más alto de segregación sexual espacial, como en el más bajo para evitar sobreestimaciones.

Palabras clave: gen SRY; grupos fecales; Odocoileus virginianus; segregación sexual espacial; SIG

\title{
Vega-Hernández, D. M., Gallina-Tessaro, S. A., Correa-Ramírez M. M., Chairez-Hernández, I., Soto- Cárdenas, M. A. (2019) White-tailed deer seasonal segregation by sex and age in free-living and fenced populations in Durango, Mexico. Acta Zoológica Mexicana (nueva serie), 35, 1-13. https://doi.org/10.21829/azm.2019.3502077
}

\begin{abstract}
White-tailed deer (Odocoileus virginianus) is a species with great economic and ecological relevance in Mexico, since it is the main game species in the country. Therefore, it is necessary to obtain reliable demographic data to improve its management. However, animal segregation movements could bias the population density estimations and demographic trends. This work aimed to analyse seasonal segregation by sex and age in free-living and fenced populations of white-tailed deer based on faecal groups. Fresh faecal groups of white-tailed deer were collected in two Wildlife Conservation Management Units (UMA in Spanish) located in Durango, Mexico: Salvador Allende and Molinillos. Faecal groups were collected every two weeks during 13 months for each UMA (from March $1^{\text {st }}, 2015$ to March $31^{\text {st }}, 2016$ for Salvador Allende, and from October $1^{\text {st }}, 2015$ to October $\left.31^{\text {st }}, 2016\right)$. The length and width of 10 faecal pellets were measured and the mean volume was calculated for each faecal group. Then, faecal groups were assigned to an age and sex category by a fuzzy set clustering technique. DNA was isolated from faecal pellets and a fragment of the SRY gene was amplified to determine the sex of the animals that deposited the faecal groups, in order to compare with the information obtained with the morphometric data of the pellets. The spatial-temporal data taken from faecal groups and the identification of age and sex were used for spatial sexual segregation coefficient (CSSE) calculation. Data about temperature, precipitation, photoperiod and vegetal cover were obtained for every season. A total of 351 fresh faecal groups were collected for both UMAs, in general, more faeces belonging to females. A lower number of faecal groups was collected in Salvador Allende (112). In both UMAs the lowest number of faecal groups was found in summer. The largest number of faecal groups was found in winter in Salvador Allende and in autumn in Molinillos. Statistic differences between segregation index between seasons was found. The sexual segregation index was higher in summer in both UMA (0.910 for Salvador Allende and 0.943 for Molinillos) when fawning occurred. By contrast, the lowest value was observed in winter (0.339) for Salvador Allende and in autumn (0.130) for Molinillos, when the breeding season occurred. Generally, reproductive behaviour determined age and sexual segregation. The highest proportion of faecal groups of juveniles was observed in spring and autumn in Salvador Allende and in summer in Molinillos. There was no correlation between sexual segregation index and environmental variables. It is necessary to consider variations in the segregation patterns in each season, since they can affect the population estimations based on the faecal counting technique. It is recommended to make the population estimates in seasons which spatial sexual segregation coefficient shows the highest and the lowest values.
\end{abstract}

Key words: SRY gene; faecal groups; Odocoileus virginianus; spatial sexual segregation coefficient; GIS 


\section{INTRODUCCIÓN}

El venado cola blanca (Odocoileus virginianus Zimmermann, 1780) es una especie de gran importancia económica y ecológica en México (Clemente et al., 2015). El manejo de especies silvestres de interés económico requiere del análisis sobre el estado de la población, tendencias demográficas y la colecta de datos como la edad y sexo para mejorar la producción animal sustentable (Janermo et al., 2017). La información acerca del número de hembras y machos dentro de una población es un indicador del estado de ésta, así como la estimación adecuada de las densidades poblacionales sirve para facilitar el cumplimiento de las leyes aplicables para el manejo de fauna, reducir la caza furtiva, estimar tasas de aprovechamiento de manera más precisa y aplicar prácticas de manejo localizado (Lindsay \& Belant, 2007; Peterson et al., 2017). El manejo exitoso de las poblaciones de ungulados requiere obtener datos confiables sobre ellas, sin embargo, el fenómeno de la segregación sexual podría sesgar las estimaciones de densidad de población y tendencias demográficas, dando como resultado la sub o sobreestimación poblacional dependiendo de la época en que se lleva a cabo la estimación. Documentar el comportamiento de segregación e identificar los factores que influyen en éste, son importantes para el entendimiento de la ecología básica de las especies y generar información crítica sobre la conservación y manejo de estas (Diefenbach et al., 2008; Lutz et al., 2015; Lutz et al., 2016).

La segregación sexual se define como el uso exclusivo por machos y hembras de distintas áreas, forraje o recursos del hábitat a diferentes escalas espaciales y temporales, siendo común entre los rumiantes polígamos y particularmente en cérvidos con dimorfismo sexual (Kie \& Bowyer, 1999). Este fenómeno se caracteriza por el diferente uso que hacen machos y hembras de los recursos o la realización de actividades en grupos del mismo sexo o edad por un periodo de tiempo (De la Cruz, 2017). Tales diferencias en el uso del área y recursos pueden causar importantes diferencias en forrajeo y otras formas de comportamiento, así como en la capacidad de sobrevivencia de los sexos, y por ende de la permanencia y persistencia de las poblaciones.

Los factores ambientales podrían influir en la segregación, particularmente en ungulados (Conradt, 1998). Han surgido diversas ideas para explicar la segregación sexual en especies de rumiantes sexualmente dimórficas no excluyentes entre sí (Barboza \& Bower, 2000; Bowyer, 2004). Existen varias hipótesis causantes de la segregación sexual y de edades como: 1) dimorfismo sexual-tamaño corporal, 2) estrategia reproductiva, 3) hipótesis de los factores sociales y 4) la conducta del forrajeo o presupuesto energético (Bowyer, 2004; Fullbright \& Ortega, 2016). Barboza y Bower (2000) agruparon las hipótesis de la segregación en dos grupos: riesgos de depredación y diferencia en la talla corporal que permite el aprovechamiento de diferente calidad de recursos forrajeros de acuerdo con la relación del tamaño del rumen y talla. Por otro lado, Sánchez-Rojas et al. (2002) comentan que la hipótesis más invocada para explicar esta segregación es la estrategia reproductiva.

El grado de segregación sexual varía entre las diferentes poblaciones de la misma especie y entre especies (Conradt, 1999). Además, las diferentes hipótesis que explican la segregación, así como los factores que la pueden ocasionar, no excluyen a los demás, por lo que existe un gran número de posibles causas de la segregación sexual; incluso las actividades humanas y cambios ambientales podrían estar afectando el comportamiento de los animales, por lo que todos esos factores deben ser estudiados y tomados en cuenta en la estimación y el manejo de las poblaciones.

Históricamente el estudio y análisis de dispersión y movimientos en ungulados mediante radiotelemetría, implica la captura o contención química, y manipulación de los individuos. Esta situación podría poner en riesgo a los ejemplares y a las personas que los manipulan, además de que podría causar sesgos en la obtención de datos de otras investigaciones debido al estrés provocado por la manipulación (Huber et al., 2003). Los grupos fecales de cérvidos han sido utilizados como índices de abundancia animal 
(Kobelkowsky-Sosa et al., 2001; Lounsberry et al., 2015) y estimaciones de densidad (Mandujano \& Gallina, 2004), fuente de identificación de animales (Brinkman et al., 2010), y como medio para determinar la dieta (Homolka et al., 2008) y los metabolitos hormonales (McCoy \& Ditchkoff, 2012). Dado que las heces pueden ser fácilmente recolectadas sin causar daños o disturbios a los individuos, el uso de este método para obtener información se torna una herramienta importante en estudios de comportamiento, ecología y manejo de las poblaciones, manteniendo el esquema de conservación y sustentabilidad (Huber et al., 2003). Por todo lo anterior, el objetivo de este trabajo fue analizar la segregación estacional por sexo y edad, a partir de los grupos fecales, en dos poblaciones de venado cola blanca tanto en vida libre como en encierro, para determinar la mejor época para llevar a cabo una estimación más precisa de la densidad poblacional.

\section{MATERIALES Y MÉTODOS}

Área de estudio. Se colectaron grupos fecales de venado cola blanca en dos Unidades de Manejo para la Conservación de Vida Silvestre (UMA) localizadas en el municipio de Durango, Durango, México. La población en vida libre se ubica en la UMA Salvador Allende. Esta UMA está localizada entre las coordenadas $24^{\circ} 71^{\prime}-24^{\circ} 05^{\prime} \mathrm{N}$ y $104^{\circ} 51^{\prime}-104^{\circ} 56^{\prime} \mathrm{O}$, a una elevación de 2,200-2,680 m. Esta UMA tiene un área de 3,200 ha. Para el invierno 2016, la densidad poblacional estimada fue de $2.52 \mathrm{venados} / \mathrm{km}^{2}$ (Vega et al., 2016). El clima de esta UMA es templado semifrío y templado semihúmedo. Los principales tipos de vegetación son bosque de encino-pino, pino-encino y bosque de encino (González et al., 2007). En la UMA Molinillos se encuentra una población de venado cola blanca en 300 ha de encierro. Para el invierno del 2016, la densidad poblacional estimada fue de 4.58 venados $/ \mathrm{km}^{2}$ (Vega et al., 2016). Esta UMA se localiza en las coordenadas $23^{\circ} 36^{\prime}-23^{\circ} 39^{\prime} \mathrm{N}$ y $104^{\circ} 59^{\prime}-105^{\circ} 06^{\prime} \mathrm{O}$, a una elevación de 2,000 a 2,680 m. El clima en esta UMA es templado semifrío y templado subhúmedo. Los principales tipos de vegetación son bosque de pino, bosque de pino-encino, bosque de encino pino y pastizal (Rosales \& Villanueva, 2014).

Colecta y clasificación de los grupos fecales. Se colectaron grupos fecales cada dos semanas por 13 meses en cada UMA. El periodo de muestreo cubrió las cuatro estaciones del año. En Salvador Allende, el periodo de muestreo ocurrió del $1^{\circ}$ de marzo de 2015 al 31 de marzo de 2016, y en Molinillos del $1^{\circ}$ de octubre 2015 al 31 de octubre 2016. Se establecieron las áreas de más actividad de venado mediante conteo de grupos fecales en transectos realizados en muestreos previos. En cada visita de colecta se hicieron dos recorridos al azar de 1,000 m para cada UMA. Se colectaron grupos fecales frescos caracterizados por la suavidad y la humedad del moco exterior que presentan los pellets. Se colocaron alrededor de 20-30 pellets de la parte superior del grupo fecal en tubos Falcon ${ }^{\circledR}$ de $50 \mathrm{ml}$ con etanol al 96\% (Lounsberry et al., 2015). Los pellets fecales restantes se depositaron en bolsas plásticas y se colocaron en congelación a $-20^{\circ} \mathrm{C}$.

Los grupos fecales fueron identificados por UMA, fecha, época del año y geolocalización. Se midió el largo y ancho de 10 de los pellets designados a congelación y se calculó su volumen. Para poder agrupar los grupos fecales por edad y sexo, se calcularon los valores de pertenencia a partir de las medias de las variables morfométricas (largo, ancho y volumen) para tres grupos (hembras adultas, machos adultos y jóvenes) mediante el algoritmo de K-medias difuso (Sánchez-Rojas et al., 2004; Sánchez-Rojas et al., 2009). Para ello se utilizó el programa Fuzzy Clustering Tool (Equihua, 2000). Para la obtención del sexo de los grupos fecales provenientes de jóvenes, así como para comprobación de la clasificación por sexo de los grupos fecales mediante la técnica de grupos difusos, se realizó una identificación de sexo mediante métodos moleculares.

Extracción de ADN fecal. Se aisló ADN mediante el método CTAB-acetato, diseñado en el laboratorio. Se extrajo ADN de dos a cuatro pellets fecales (dependiendo del tamaño del pellet) mantenidos en etanol al 96\%, donde cada pellet se trató como muestra independiente. Se dejaron secar los pellets por 45 min a temperatura ambiente en cajas Petri esterilizadas con alcohol al $96 \%$ y luz UV. Ya secas, se colocaron 0.5 $\mathrm{g}$ de muestra en microtubos de $1.5 \mathrm{ml}$ y se agregó $1 \mathrm{ml}$ de buffer de extracción (2\% CTAB, 100 mM TRIS, 
pH 8, 20 Mm EDTA, pH 8, $1.4 \mathrm{M} \mathrm{NaCl}$ y $1 \%$ de PVP) y $5 \mu \mathrm{L}$ de 2 -mercaptoetanol, por tubo. Los tubos se agitaron mediante vórtex por $10 \mathrm{~s}$ a $3,400 \mathrm{rpm}$ y se colocaron en digestión por 1 hora a $65^{\circ} \mathrm{C}$. Después de esa hora, se agregó $50 \mu \mathrm{L}$ de Proteinasa $\mathrm{K}$ a los tubos y se llevó a cabo una digestión de una hora más a $65^{\circ} \mathrm{C}$. Se centrifugaron los tubos por $15 \mathrm{~min}$ a $13,200 \mathrm{rpm}$ para separar la fase sólida y se transfirió el sobrenadante a nuevos microtubos estériles y se centrifugaron por $15 \mathrm{~min}$ a 13,200 rpm. El sobrenadante se transfirió a nuevos microtubos estériles y se agregó $400 \mu \mathrm{L}$ de cloroformo-alcohol isoamílico (24:1). Después, los tubos se agitaron mediante vórtex por $10 \mathrm{~s}$ a 3,400 rpm y se centrifugaron por 6 min a 13,200 $\mathrm{rpm}$. Se separó la fase superior y se transfirió a nuevos microtubos y se agregó $300 \mu \mathrm{L}$ de acetato de amonio (3M, pH 5.2) y $600 \mu \mathrm{L}$ de alcohol isopropílico. Se dejaron los tubos a $-20^{\circ} \mathrm{C}$ durante toda la noche. Después se centrifugaron los tubos por $15 \mathrm{~min}$ a 13,200 rpm. Se desechó el sobrenadante y se dejó la pastilla de ADN en la parte inferior del tubo. Se lavó la pastilla con $500 \mu \mathrm{L}$ de etanol al $80 \%$ y centrifugación por 6 min a 13,200 rpm, este paso se realizó en dos ocasiones. Finalmente se dejaron secar los tubos a temperatura ambiente. El ADN fue rehidratado con $55 \mu \mathrm{L}$ de agua grado biología molecular. Se calculó la pureza y cantidad del ADN mediante espectrofotómetro Nanodrop® 2000. La integridad del ADN se observó en geles de agarosa al $1 \%$ teñidos con bromuro de etidio.

Identificación de sexo en los grupos fecales. Para determinar el sexo de los animales que depositaron los grupos fecales colectados, se amplificó el fragmento del gen SRY con el par de oligonucleótidos SRY forward: CAT CTT GTC TGT GTG TCG TG y SRY reverse: CGG GTA GTG TCG TTT GTC TA (Lounsberry et al. 2015) mediante PCR. Se utilizaron tres muestras de tejido proveniente de tres machos adultos cazados en Salvador Allende (durante la época de caza) como controles positivos. Las concentraciones finales por reacción de PCR fueron 100-150 $\eta \mathrm{g} / \mu \mathrm{L}$ DNA, $2.5 \mathrm{mM} \mathrm{MgCl}, 0.5 \mathrm{mM}$ dNTP's, $0.6 \mathrm{pM}$ primers y 0.750 unidades de Taq ADN polimerasa. El perfil térmico que se utilizó fue 15 min a $95^{\circ} \mathrm{C}$ de desnaturalización inicial, 35 ciclos de $30 \mathrm{~s} \mathrm{a} 94^{\circ} \mathrm{C}, 1.30 \mathrm{~min}$ a $58^{\circ} \mathrm{C}$ y 1 min a $72^{\circ} \mathrm{C}$, y finalmente, 10 min a $72^{\circ} \mathrm{C}$ de elongación final.

En cada reacción de PCR llevada a cabo, se incluyó una muestra de ADN de tejido como control positivo y agua como control negativo. Se observaron los productos de PCR en geles de agarosa al $1 \%$ teñidos con bromuro de etidio. En cada gel se agregó el marcador de peso molecular, los controles positivo y negativo. Las muestras que no mostraron amplificación fueron repetidas en todo el proceso. Entonces, las muestras que no mostraron amplificación en los geles fueron tomadas como hembras y las muestras que mostraron amplificación (banda de $\sim 200 \mathrm{pb}$ ) fueron asignadas como machos. Las muestras que mostraron bandas difusas no se tomaron en cuenta para el estudio. Algunas identificaciones de sexo mediante método molecular fueron corroboradas con los registros directos de los animales en campo.

Análisis espacial de segregación. Los datos espaciotemporales tomados de los grupos fecales, así como su identificación de edad, sexo y estación del año fueron ubicados en mapas construidos con QGIS 2.18 (QGIS, 2018). A partir de los mapas de la superficie muestreada, se dividieron en cuadros y se estimó el grado de segregación espacial por estación del año mediante la fórmula propuesta por Conradt (1999):

$$
\operatorname{CSSE}=\sqrt{\left(1-\frac{N-1}{X \cdot Y} \cdot \sum_{i=1}^{k} \frac{x_{i} y_{i}}{n_{i}-1}\right)}
$$


Donde:

CSSE: Coeficiente de Segregación Sexual Espacial ( 0 = no hay segregación, 1 = segregación completa)

$X=$ Número total de grupos fecales identificados como machos (adultos y jóvenes)

$Y=$ Número total de grupos fecales identificados como hembras (adultas y jóvenes)

$N=$ Número total de grupos fecales $(\mathrm{X}+\mathrm{Y})$

$x_{i}=$ Número de machos en el iésimo cuadro de la retícula

$y_{i}=$ Número de hembras en el iésimo cuadro de la retícula

$n_{i}=$ Número de animales en el iésimo cuadro de la retícula $\left(x_{i}+y_{i}\right)$

$k=$ Número de cuadros en la retícula

Variables ambientales. Para obtener información acerca de la cobertura vegetal de los estratos arbustivo y herbáceo se trazaron líneas de intercepción de Canfield para cada estación del año. Las líneas se iniciaron en el mismo punto de inicio que el recorrido aleatorio para muestreo de heces y tuvieron una longitud de 20 $\mathrm{m}$. La información sobre temperatura diaria, precipitación diaria, fotoperiodo (horas luz al día) fue proporcionada por la Comisión Nacional del Agua (CONAGUA) y el Instituto Mexicano de Tecnología del Agua (IMTA).

Análisis estadístico. Para saber si existía diferencia entre el grado de segregación entre las diferentes épocas del año se condujo una prueba no paramétrica Kruskall-Wallis mediante el programa PAST versión 3 (Natural History Museum, University of Oslo). Para conocer la relación entre el valor del índice de segregación sexual espacial y las variables ambientales se realizó un análisis de correlación no paramétrico de Spearman con los valores obtenidos por cada estación del año tanto de segregación como de las variables ambientales. Este análisis se realizó mediante el programa estadístico SAS versión 9.0. (SAS Institute, Cary, N.C.).

\section{RESULTADOS}

Se colectaron 385 grupos fecales frescos para ambas UMA en todas las épocas del año. En Salvador Allende se colectó un menor número de grupos fecales (112) comparado con la UMA Molinillos (273). En ambas UMA se encontró el menor número de grupos fecales en verano (Tabla 1). El mayor número de grupos fecales se encontró en invierno en Salvador Allende y en otoño en Molinillos. La época con el segundo mayor número de heces fue primavera en ambas UMA. En general, se encontraron más grupos fecales pertenecientes a hembras en ambas UMA para todas las edades y estaciones (Tabla 1).

Tabla 1. Grupos fecales colectados por época del año en dos UMA de Durango, México, categorizados por edad mediante morfometría de pellets fecales, y determinación del sexo utilizando amplificación del marcador del gen SRY de ADN fecal $(\mathrm{H}=$ hembras, $\mathrm{M}=$ macho).

\begin{tabular}{ccccccccccc}
\hline & \multicolumn{4}{c}{ Salvador Allende } & \multicolumn{9}{c}{ Molinillos } \\
\cline { 2 - 13 } & \multicolumn{1}{c}{ Adultos } & \multicolumn{1}{c}{ Jóvenes } & \multicolumn{4}{c}{ Adultos } & Jóvenes & M \\
\hline Estación & H & M & H & M & Total & H & M & H & M & Total \\
\hline Primavera & 10 & 2 & 15 & 9 & 36 & 16 & 3 & 19 & 18 & 56 \\
Verano & 6 & 1 & 2 & 4 & 13 & 3 & 6 & 6 & 21 & 36 \\
Otoño & 8 & 1 & 6 & 8 & 23 & 40 & 13 & 26 & 51 & 130 \\
Invierno & 16 & 3 & 12 & 9 & 40 & 20 & 2 & 14 & 15 & 51 \\
Total & 40 & 7 & 35 & 30 & 112 & 79 & 24 & 65 & 105 & 273 \\
\hline
\end{tabular}

La clasificación para edad y sexo mediante algoritmo K-medias difuso clasificó correctamente 87.4\% de los grupos fecales de hembras adultas (105 de 119 grupos fecales clasificadas como hembras mediante métodos moleculares). Respecto a los machos, se pudo clasificar exitosamente un $90.3 \%$ de los 
grupos fecales de machos adultos (28 de 31 grupos fecales identificados como machos mediante métodos moleculares).

Hubo un mayor número de hembras que de machos en la población en vida libre. En invierno existió un mayor número de hembras por macho en ambas UMA, mientras que en el verano se observó el efecto contrario (Tabla 2). Respecto a la edad, se observó mayor presencia de juveniles que de adultos en ambas UMA. La mayor proporción de grupos fecales de jóvenes respecto a los de adultos se observó en primavera en Salvador Allende y en verano en Molinillos (Tabla 3).

En Salvador Allende, en primavera, los grupos fecales se encontraron cercanos. En verano, se observó el menor número de grupos fecales, mientras que en otoño aumentó el número de grupos fecales de ambos sexos y edades y continuó hasta el invierno, donde hubo el mayor número de grupos fecales (Fig. 1). En Molinillos, en el verano se presentó el menor número de grupos fecales que pertenecían, en su mayoría, a machos. En otoño es cuando se observó la mayor cantidad de grupos fecales, de jóvenes y adultos, formando dos grupos (Fig. 2). Estos grupos se mantuvieron hasta el invierno, aunque con menores valores.

Tabla 2. Razón macho:hembra estación del año obtenida a partir de morfometría de pellets fecales e identificación de sexo por amplificación del marcador del gen SRY del ADN fecal en dos UMA de Durango México.

\begin{tabular}{ccc}
\hline Estación & Salvador Allende & Molinillos \\
\hline Primavera & $1: 1.36$ & $1: 1.66$ \\
Verano & $1: 1.60$ & $1: 0.33$ \\
Otoño & $1: 1.55$ & $1: .03$ \\
Invierno & $1: 2.33$ & $1: 2.17$ \\
General & $1: 2.02$ & $1: 1.11$ \\
\hline
\end{tabular}

Tabla 3. Razón adulto:juvenil por estación del año obtenida a partir de la morfometría de los pellets fecales en dos UMA de Durango, México.

\begin{tabular}{ccc}
\hline Estación & Salvador Allende & Molinillos \\
\hline Primavera & $1: 2.00$ & $1: 1.94$ \\
Verano & $1: 0.85$ & $1: 3.00$ \\
Otoño & $1: 1.55$ & $1: 1.45$ \\
Invierno & $1: 1.10$ & $1: 1.31$ \\
General & $1: 1.38$ & $1: 1.65$ \\
\hline
\end{tabular}

Respecto al grado de segregación espacial, mediante la prueba de Kruskall-Wallis se pudieron observar diferencias estadísticas entre estaciones del año $\left(\chi^{2}=16.64, P=0.0001\right)$. Se observó un incremento de segregación en verano en ambas UMA. El nivel más bajo de segregación espacial se observó en invierno en Salvador Allende y en otoño para Molinillos (Tabla 4). No se encontró correlación significativa entre el grado de segregación espacial y alguna de las variables ambientales para ambas UMA (Tabla 4).

\section{DISCUSIÓN}

Primeramente, la clasificación de los grupos fecales por medio de la morfometría de los pellets resultó ser una buena herramienta para clasificar por edad y sexo. La técnica utilizada del algoritmo K-medias difuso para separar grupos de edades ha mostrado alto porcentaje de correcta clasificación de los grupos fecales (Sánchez-Rojas et al., 2004; Sánchez-Rojas et al., 2009). Igualmente se obtuvo en los grupos fecales de adultos, un alto porcentaje de correcta clasificación del sexo comparado con los resultados obtenidos mediante la amplificación del marcador del gen SRY. Por lo que se consideró confiable esta metodología para separar adultos (hembras y machos) de jóvenes. 
Tabla 4. Valores del coeficiente de segregación sexual espacial y medias de precipitación, temperatura, fotoperiodo (horas luz al día) y porcentaje de cobertura vegetal en dos UMA de Durango, México; y coeficiente de correlación no paramétrico entre el grado de segregación sexual espacial con las variables ambientales.

\begin{tabular}{cccccc}
\hline UMA/Estación & Grado de segregación & Precipitación & Temperatura & Fotoperiodo & Cobertura \\
\hline Salvador Allende & & & & & \\
Primavera & 0.386 & 2.6 & 9.2 & 13.31 & 36.5 \\
Verano & 0.910 & 13.8 & 11.2 & 12.95 & 75.2 \\
Otoño & 0.454 & 0.0 & 4.0 & 11.15 & 66.5 \\
Invierno & 0.339 & 0.0 & 2.7 & 11.09 & 57.4 \\
Correlación & - & 0.6324 & 0.8000 & 0.4000 & 0.8000 \\
$P$ & - & 0.3675 & 0.2000 & 0.6000 & 0.2000 \\
\hline Molinillos & & & & & \\
Primavera & 0.282 & 1.1 & 2.9 & 12.92 & 57.8 \\
Verano & 0.943 & 8.9 & 11.3 & 12.99 & 85.8 \\
Otoño & 0.130 & 0.3 & 4.8 & 11.28 & 54.4 \\
Invierno & 0.250 & 0.0 & 0.3 & 11.15 & 51.9 \\
Correlación & - & 0.8000 & 0.4000 & 0.8000 & 0.8000 \\
$p$ & - & 0.2000 & 0.6000 & 0.2000 & 0.2000 \\
\hline
\end{tabular}

En Molinillos se encontró mayor número de grupos fecales frescos que en Salvador Allende, esto pudo deberse a que en Molinillos el área de movimiento tiene un límite por el cercado y los animales tienen un ámbito hogareño restringido, por lo que los grupos fecales son más probables de ser encontrados y ocasiona que el grado de segregación se disminuya. Cabe mencionar que en la UMA Salvador Allende es permitida la cacería, esto podría provocar la baja presencia de grupos fecales pertenecientes a adultos, principalmente de machos (Tabla 1). Según Karns et al. (2011) la presión de la cacería y los vehículos también pueden hacer que se muevan los animales con mayor frecuencia, sin embargo, no se lleva a cabo actividad cinegética en Molinillos. Por su parte, Kie y Bowyer (1999) documentaron en su estudio con venado cola blanca, que la depredación puede afectar la segregación de los individuos dependiendo del sexo. No obstante, esos factores no fueron estrictamente medidos en este estudio ya que no hay registros de depredadores en ambas UMA.

La separación espacial de sexos fuera de la época de apareamiento está presente en casi todos los rumiantes polígamos (Pérez-Solano et al., 2016). El grado de variación espaciotemporal durante la segregación de esas especies es muy variable. Se cree que indirectamente o de manera variable, evitar la competencia entre los sexos es la causante de la segregación. Esta hipótesis incluye la idea del tamaño corporal.

También se ha propuesto que las hembras competitivamente excluyen a los machos de algunos sitios con mejor calidad de alimentos y protección para sus crías (Barboza \& Bowyer, 2000). Se ha postulado para ciervo rojo, que los machos son menos tolerantes a sitios con poca biomasa que las hembras (Kie \& Bowyer, 1999). Otra causa de segregación puede ser la estructura del paisaje, o el ambiente ya que la variación ambiental puede afectar la dispersión (Long et al., 2005). Brinkman et al. (2005) comentan que, en respuesta a las severas condiciones del clima, los venados podrían minimizar el movimiento para conservar energía. Así también, Conradt (1999) y Rosenberry et al. (2000) comentan que la cantidad de cobertura vegetal puede provocar la segregación en cérvidos. Long et al. (2005) encontraron una correlación entre la distancia de movimiento y dispersión de venado cola blanca y la cobertura forestal. Por su parte, para venado bura (Odocoileus hemionus) en el Desierto Chihuahuense, Pérez-Solano et al. (2016) mencionan que el tipo de vegetación de un sitio afecta la densidad de venados en un área, y De la Cruz (2017) encontró mayor presencia de grupos fecales en transectos con mayor presencia de vegetación, y asociación con ciertas características de la vegetación y el sexo, obtenido de los grupos fecales. 

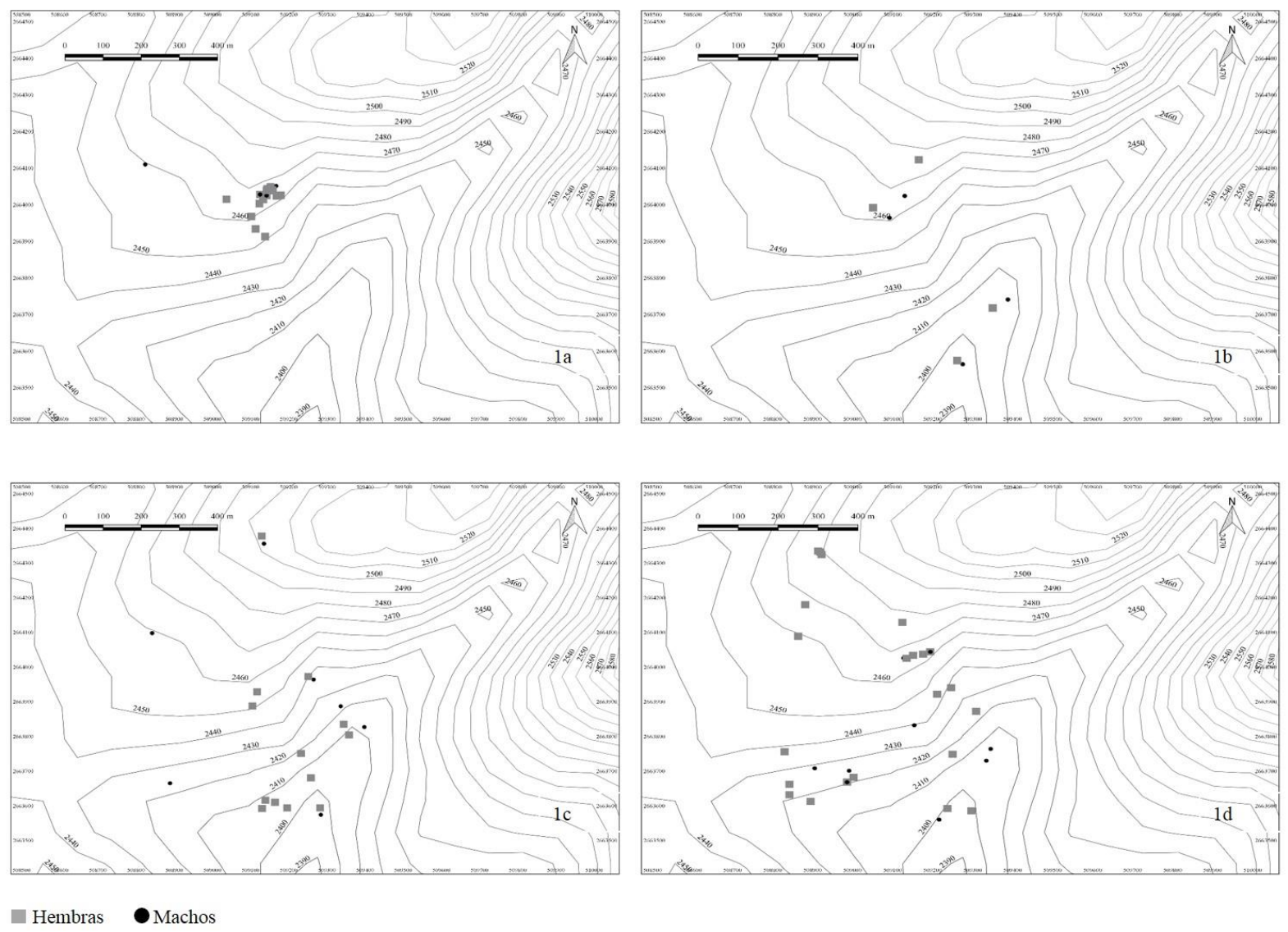

- Hembras Machos

Figura 1. Segregación por edad y sexo de venado cola blanca en la UMA Salvador Allende a partir de grupos fecales en primavera (1a), verano (1b), otoño (1c) e invierno (1d).

Sin embargo, Peterson et al. (2017) no encontraron relación entre la segregación y cobertura vegetal. Brinkman et al. (2005) y Lutz et al. (2016) no encontraron diferencias entre distancias recorridas o elección de un ámbito hogareño para venado cola blanca entre un sitio con alta cobertura forestal y un ecosistema completamente agrícola. Long et al. (2005) mencionan que el venado cola blanca es una especie generalista por lo que se mueve de forma similar en sitios con poca o alta cobertura forestal. Esto podría explicar que no exista correlación entre el grado de segregación espacial y las condiciones ambientales en el presente estudio.

A partir de esto, se asume que la segregación y movimientos realizados por los animales observados en este estudio, son el resultado de una estrategia reproductiva. Esta hipótesis menciona que antes de la época reproductiva los machos hacen uso del hábitat donde hay más recursos de manera que puedan incrementar su masa corporal y acceder a más hembras en la época de celo, y a su vez, las hembras preñadas deben asegurar la sobrevivencia de sus crías, por lo que en verano harán uso de los recursos de diferente manera buscando sitios con cobertura vegetal que sirva de protección para las crías y donde a la vez puedan obtener alimento de mejor calidad para la lactancia (Sánchez-Rojas et al. 2002).

Los eventos de dispersión del venado cola blanca usualmente inician durante dos periodos: en época reproductiva (otoño e invierno) y en época de nacimientos de los cervatos (entre primavera y verano; Lutz et al. 2015). Entonces, la baja presencia de grupos fecales, principalmente de hembras, en ambas UMA, y 
el alto grado de segregación espacial en el verano, coincide con la época de pariciones. Las hembras de venado cola blanca muestran patrones de comportamiento complejos durante la preñez y la crianza de los cervatos: probablemente el tipo de áreas utilizadas por las hembras se modifica, así como el forrajeo y las estrategias para evitar a los depredadores buscando áreas con cierta cobertura vegetal de protección (SotoWerschitz et al., 2018). Así también, Long et al. (2005) y Kolodzinski et al. (2010) observaron que, en verano, las hembras se dispersaron dada la época de pariciones. Durante la época de partos, las hembras preñadas buscan aislamiento y muestran comportamiento violento hacia otros venados, incluyendo familiares (Lutz et al. 2016).
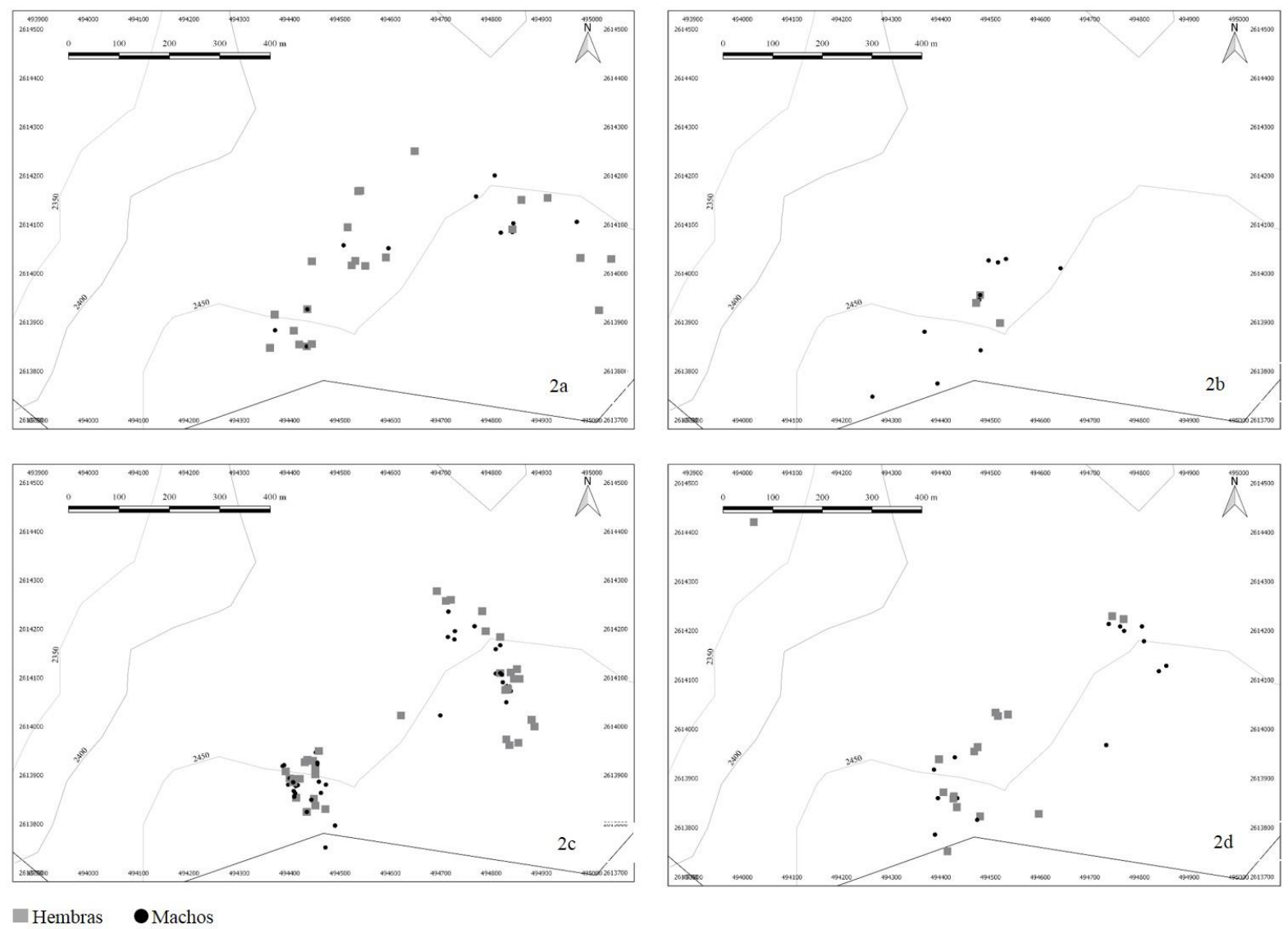

Figura 2. Segregación por edad y sexo de venado cola blanca en la UMA Molinillos a partir de grupos fecales en primavera (2a), verano (2b), otoño (2c) e invierno (2d).

El aumento de grupos fecales encontrados y el bajo nivel de segregación espacial en otoño para Molinillos e invierno para Salvador Allende, puede ser indicativo de la época reproductiva. Conforme el estro se acerca, las hembras se concentran dentro de las áreas de mayor actividad, lo cual puede incrementar la oportunidad de los machos de detectar a las hembras enfocándose a las actividades reproductivas dentro de un área pequeña (Karns et al. 2011; Peterson et al., 2017). Con base en estos resultados, la época reproductiva se podría estar presentando a finales de otoño en Molinillos, mientras que en Salvador Allende se extiende al invierno. Esto puede ser explicado por la edad de los individuos, ya que en Salvador Allende hay menos proporción de adultos. Se ha observado que hembras de un año y medio de edad, y hasta hembras de seis meses, pueden entrar en celo mucho después que las hembras adultas (Karns et al., 2011). Probablemente los individuos se reúnen para la reproducción de manera tardía, consecuencia de un estro retrasado. Hembras jóvenes exhiben celos tardíos y pueden provocar que se extienda la época reproductiva 
lo que explicaría parcialmente porque los machos buscan las hembras en invierno para aumentar las oportunidades de reproducirse (Lutz et al., 2016).

Se observó en este estudio una mayor proporción de jóvenes poco antes de entrar a la época de apareamiento. La mayor proporción de jóvenes se encontró en otoño en Salvador Allende y en verano en Molinillos (Tabla 4). Esto concuerda con Janermo et al. (2017) al observar que, al inicio de la época reproductiva, la proporción de machos adultos fue baja, pero incrementó continuamente y alcanzó un nivel alto teniendo un pico sobre la época reproductiva.

\section{CONCLUSIONES}

En general, la segregación sexual y de edad estuvo regida por una estrategia reproductiva ya que ocurre en la época de pariciones y disminuye en la época reproductiva. Por lo anterior es importante estudiar y registrar estos cambios ya que son indicativos del inicio y término de cada una de estas épocas. Sin embargo, hay que tomar en cuenta que existen otros factores que pueden provocar la segregación y desplazamiento de los individuos, tal como las características del hábitat o ambientales, relaciones sociales y actividades humanas. El seguimiento y registro de esos movimientos proveen información acerca de sus causas para realizar actividades de manejo en las poblaciones.

Hay que considerar las variaciones en los patrones de segregación de cada sexo y edad en cada época del año, ya que puede afectar los resultados de estimaciones de la densidad poblacional mediante la técnica de conteo de grupos fecales. Se recomienda realizar las estimaciones de población de preferencia en las épocas del año donde se presente el valor más alto y el más bajo del grado de segregación sexual espacial para evitar sub o sobreestimaciones. Asimismo, se requiere más información sobre factores que provoquen la segregación de los individuos para el manejo adecuado de las poblaciones.

\section{LITERATURA CITADA}

Barboza, P. S., Bowyer, R. T. (2000) Sexual segregation in dimorphic deer: a new gastrocentric hypothesis. Journal of Mammalogy, 81 (2), 473-489.

Bowyer, R. (2004) Sexual segregation in ruminants: definitions, hypothesis, and implications for conservation and management. Journal of Mammalogy, 85 (6), 1039-1052.

Brinkman, T. J., Deperno, C. S., Jenks, J. A., Harlodson, B. S., Osborn, R. G. (2005) Movement of female white-tailed deer: effects of climate and intense row crop agriculture. Journal of Wildlife Management, 69 (3),1099-1111.

Brinkman, T. J., Person, D. K., Schwartz, M. K., Pilgrim, K. L., Colson, K. E., Hundertmark, K. J. (2010) Individual identification of Sitka black deer (Odocoileus hemionus sitkensis) using DNA from fecal pellets. Conservation Genetic Resources, 2, 115-188.

Clemente, F., Cessa, V., Cortez, C., Tarango, L., Arenas, P. (2015) Commercial extenders and freezing curves for the preservation of sperm cells of white-tailed deer (Odocoileus virginianus). Journal of Applied Animal Research, 43 (4), 468-473.

Conradt, L. (1998) Measuring the degree of sexual segregation in group-living animals. Journal of Animal Ecology, 67, 217-226.

Conradt, L. (1999) Social segregation is not a consequence of habitat segregation in red deer and feral soay sheep. Animal Behavior, 57, 1151-1157.

De la Cruz, N. P. (2017) Estudio de la segregación sexual del venado bura en la reserva de la biosfera de Mapimí, evaluando sus consecuencias ecológicas. Tesis Maestría. Universidad Autónoma del Estado de Hidalgo, México, 64 p. 
Diefenbach, D. R., Long, E. S., Rosenberry, C. S., Wallingford, B. D., Smith, D. R. (2008) Modeling distribution of dispersal distances in male white-tailed deer. Journal of Wildife Management, 72 (6), 1296-1303.

Equihua, M. (2000) Fuzzy clustering tool program. Xalapa, México. Instituto de Ecología, A.C.

Ezcurra, E., Gallina, S. (1981) Biology and population dynamics of white-tailed deer in Northwestern Mexico, pp. 78-108. En: Folliott, P. F., Gallina, S. (Eds). Deer biology, habitat requirements, and management in western North America. Instituto de Ecología, A.C., Ciudad de México, México.

Fullbright, T., Ortega, S. (2016) Ecología y Manejo de venado cola blanca. Editorial del Colegio de Postgraduados. Texcoco, Estado de México, México. 340 pp.

González, M., González, M., Márquez, M. (2007) Vegetación y ecorregiones de Durango. Plaza y Valdez. Ciudad de México, México, 220 p.

Homolka, M., Heroldová, M., Bartoš, L. (2008) White-tailed deer winter feeding strategy in area shared with other deer species. Folia Zoologica, 57, 283-293.

Huber, S., Bruns, U., Arnold, W. (2003) Genotyping hervibore feces facilitating their further analyses. Wildlife Society Bulletin, 31, 92-697.

Janermo, A., Jansson, G., Månsson, J. (2017) Temporal variations in activity patterns during rutimplications for survey techniques of red deer, Cervus elaphus. Wildlife Research, 44 (2), 106-113.

Karns, G. R., Lancia, R. A., DePerno, C. S., Conner, M. C. (2011) Investigation of adult male whitetailed deer excursions outside their home range. Southeastern Naturalist, 10 (1), 39-52.

Kie, J. G., Bowyer, T. (1999) Sexual segregation in white-tailed deer: density-dependent changes in use of space, habitat selection, and dietary niche. Journal of Mammalogy, 80 (3), 1004-1020.

Kobelkowsky-Sosa, R., Palacio, J., Clemente, F., Mendoza, G., Herrera, J., Gallegos, J. (2001) Calidad del hábitat y estado poblacional del venado cola blanca (Odocoileus virginianus, Hays) en ranchos cinegéticos de la Sierra Fría, Aguascalientes. Revista Chapingo Serie Ciencias Forestales y del Ambiente, 6, 125-130.

Kolodzinski, J. J., Tannenbaaum, L. V., Muller, L. I., Osborn, D. A., Adams, K. A., Conner, M. C., Ford, W. M., Miller, K. V. (2010) Excursive behaviours by female white-tailed deer during estrus at two mid-Atlantic sites. The American Midland Naturalist, 163, 366-373.

Lindsay, A. R., Belant, J. (2007) A simple and improved PCR based technique for white-tailed deer (Odocoileus virginianus) sex identification. Conservation genetics. Technical note. Springer.

Long, E. S., Diefenbach, D. R., Rosenberry, C. S., Wallingford, B. D., Grund, M. D. (2005) Forest cover influences dispersal distance of white-tailed deer. Journal of Mammalogy, 86 (3), 623-629.

Lounsberry, Z. T., Forrester, T. D., Olegario, M. T., Brazeal, J. L., Wittmer, H. U., Sacks, B. N. (2015) Estimating sex-specific abundance in fawning areas of high-density Columbian black-tailed deer using fecal DNA. Journal of Wildlife Management, 79, 39-49.

Lutz, C. L., Diefenbach, D. R., Rosenberry, C. S. (2015) Population density influences dispersal in female white-tailed deer. Journal of Mammalogy, 96 (3), 494-501.

Lutz, C. L., Diefenbach, D. R., Rosenberry, C. S. (2016) Proximate influences on female dispersal in white-tailed deer. Journal of Wildlife Management, 80 (7), 1218-1226.

Mandujano, S., Gallina, S. (2004) Dinámica poblacional del venado cola blanca (Odocoileus virginianus) en un bosque tropical seco, pp. 317-330. En: Sánchez, V., Medellín, R. A. (Eds). Contribuciones mastozoológicas en homenaje a Bernardo Villa. Instituto de Biología e Instituto de Ecología, UNAM, México.

McCoy, J. C., Ditchkoff, S. S. (2012) Patterns of fecal hormones in a fenced population of white-tailed deer. Wildlife Society Bulletin, 36, 641-646.

Pérez-Solano, L. A., Gallina, S. A., Sánchez-Rojas, G. (2016) Individual variation mule deer (Odocoileus hemionus) and home range in the Chihuahuan Desert, Mexico. Journal of Mammalogy, 97 (4), $1228-1237$.

Peterson, B. E., Storm, D. J., Norton, A. S., Van Deelen, T. R. (2017) Landscape influence on dispersal of yearling male white-tailed deer. The Journal of Wildlife Management, 81 (8), 1449-1456. 
QGIS Development Team (2018) QGIS Geographic Information System. Open Source Geospatial Foundation Project. Disponible en: https://qgis.org

Rosales, S., Villanueva, J. (2014) Efecto de la deforestación sobre la variabilidad climática en bosques de Pinus duranguensis Martínez en el municipio de Durango, pp. 83-110. En: Pérez, M. R. (Comp.). Efecto de la deforestación sobre la variabilidad climática en cinco bosques de coníferas. SAGARPA, INIFAP, CENID, COMEF, Mexico.

Rosenberry, C. S., Conner, M. C., Lancia, R. A. (2000) Behavior and dispersal of white-tailed deer during the breeding season. Canadian Journal of Zoology, 79, 171-174.

Sánchez-Rojas, G., Aguilar-Miguel, C., Hernández-Cid, E. (2009) Estudio poblacional y uso de hábitat por el venado cola blanca (Odocoileus virginianus) en un bosque templado de la Sierra de Pachuca, Hidalgo, México. Tropical Conservation Science, 2 (2), 204-214.

Sánchez-Rojas, G., Gallina, S., Equihua, M. (2002) Segregación sexual y por edad del venado bura (Odocoileus hemionus) en el desierto Chihuahuense. Memorias VII Simposio Sobre Venados en México.

Sánchez-Rojas, G., Gallina, S., Equihua, M. (2004) Pellet morphometry as a tool to distinguish age and sex in the mule deer. Zoo Biology, 23, 139-146.

Soto-Werschitz, A., Mandujano, S., Gallina, S. (2018) Home-range analyses and habitat use by whitetailed deer females during breeding season. Therya, 9 (1), 1-6.

Vega, D., Gutiérrez, M., Reyes, J. (2016) Densidad poblacional de venado cola blanca (Odocoileus virginianus) en dos UMAs de Durango, México. Vidsupra, 8 (2), 24-28. 